\title{
A bibliometria na (e além da) avaliação
}

\author{
Richard Romancini \\ Doutor; Universidade de São Paulo, São Paulo, SP, Brasil; \\ richard.romancini@gmail.com
}

GINGRAS, Y. Os desvios da avaliação da
pesquisa: o bom uso da bibliometria.
Tradução de Carlos Deanne. Rio de Janeiro:

Ed. da UFRJ, 2016.

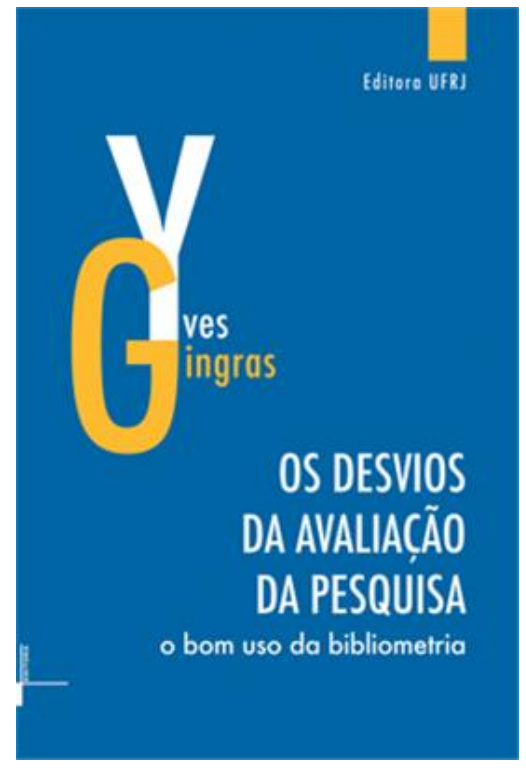

Resumo: Resenha do livro Os desvios da avaliação da pesquisa: o bom uso da bibliometria, de Yves Gingras, que destaca o caráter oportuno e de síntese da obra, que tem como objetivo apresentar e discutir os métodos bibliométricos, particularmente, em termos de seu uso na avaliação da pesquisa científica. $O$ livro apresenta uma perspectiva crítica sobre a temática, mas sem negar a importância da bibliometria, procurando discernir os usos adequados dos "abusos" praticados a partir da utilização, com baixa reflexividade, dos indicadores quantitativos bibliométricos na avaliação da ciência.

Palavras-chave: Avaliação Científica. Bibliometria. Pesquisa Científica. Cientometria.

Oportuno, no contexto atual de centralidade dos processos avaliativos da atividade científica, a partir de indicadores quantitativos, o livro Os desvios da avaliação da pesquisa: o bom uso da bibliometria fornece ao leitor um panorama de questões que relacionam a bibliometria à ciência. A tradução foi feita a partir do original francês (Les dérives de l'évaluation de la recherche: $d u$ bon usage de la bibliométrie), de 2014, sendo que há, também, uma tradução em 
língua inglesa (Bibliometrics and research evaluation: uses and abuses), editada em 2016. A obra, de Yves Gingras, professor titular de História e Sociologia das Ciências, na Universidade do Quebec, em Montreal (UQAM), cumpre os objetivos a que se propõe: apresentar, sinteticamente, os métodos bibliométricos, demonstrando o campo de aplicação dos mesmos, que inclui o âmbito da avaliação da pesquisa.

Embora sucinto, o livro cobre bem a temática, escapando de tecnicidades que poderiam tornar a discussão cansativa. Ao contrário, a matéria é abordada, ao longo dos quatro capítulos do trabalho, de maneira acessível e sem superficialidade.

O livro é também valorizado por uma "Apresentação", de Carlos Vainer, professor da Universidade Federal do Rio de Janeiro (UFRJ), que destaca como questões discutidas pelo trabalho repercutem no contexto de países periféricos como o Brasil. Desse modo, Vainer (2016, p. 14) postula que os sistemas de avaliação têm como efeito agirem como um instrumento de produção e reprodução do que chama de "colonialidade do saber universitário", ou seja, atuam na criação de hierarquias sem fundamentos na relevância e no mérito científico.

Em relação ao conteúdo específico do livro, a discussão da chamada bibliometria avaliativa está no cerne do trabalho. No entanto, Gingras (2016) não produz um libelo contra a avaliação científica, nem contra todo o uso da bibliometria, mas sim aponta os limites dos indicadores bibliométricos, de modo a criticar os frequentes abusos relacionados à sua utilização em processos de avaliação. Como o título da obra indica, o autor defende o "bom" uso da bibliometria, o que significa, em outras palavras, utilizar as medidas quantitativas “[...] em contexto como auxílio à decisão e não como veredito absoluto e indiscutível.” (GINGRAS, 2016, p. 87).

Nesta perspectiva, o plano da obra é coerente, começando com um capítulo que descreve a trajetória histórica do método, desde sua origem, em meados dos anos 1920, voltado à gestão das coleções de revistas pelos bibliotecários, passando pelo desenvolvimento, após a Segunda Guerra, do índex de citações do Institute for Scientific Information (ISI), até o encontro da 
bibliometria com a cientometria e com a sociologia da ciência, no apoio às políticas científicas, a partir da década de 1970, e, desde os anos de 1980, com a bibliometria passando a ser usada na avaliação da atividade científica. Como explica o autor, o uso dos bancos de dados informatizados e o interesse dos governos/instituições internacionais por métricas, a respeito do desenvolvimento científico dos países, tornaram a bibliometria uma ferramenta usual de avaliação. Sendo assim, ela passou a ser associada mecanicamente a esta atividade, com uma utilização, por vezes, pouco lúcida dos métodos bibliométricos (GINGRAS, 2016).

Um exemplo dado pelo autor dessa "bibliometria selvagem" (GINGRAS, 2016, p. 34), sem rigor metodológico, é o uso da bibliometria (possibilitado pelo avanço da internet) em escala individual, algo que fora evitado pelos trabalhos bibliométricos antes dos anos 2000, em favor dos estudos em uma escala agregada (grandes laboratórios, universidades, países).

Por outro lado, Gingras (2016) defende a utilidade da bibliometria na análise da dinâmica global da ciência, aspecto discutido no segundo capítulo, no qual argumenta, em resumo, que, ao cobrirem um longo período temporal, os bancos de dados de citações "[...] permitem estudar de múltiplas formas as transformações sociais e cognitivas da ciência em várias disciplinas." (GINGRAS, 2016, p. 47). As aplicações apresentadas - em termos das práticas de coletivização e internacionalização das ciências, evidenciadas pelos dados de coautorias e pelas redes científicas - dão força ao argumento. Os dados quantitativos agregados, que a bibliometria pode prover, são fundamentais para perceber tendências e observar realidades, como o crescimento da produção científica da China e a diminuição ocorrida na Rússia nas últimas décadas.

Também importante, neste capítulo, é a discussão das diferenças entre os campos disciplinares, que os próprios dados bibliométricos podem evidenciar, por exemplo, no caso dos números médios de citações dos pesquisadores. Desse modo, destacando o caráter contextual das práticas de citação, conclui o autor que "[...] o número absoluto de citações significa geralmente pouca coisa em si mesmo [...] e deve sempre ser remetido às práticas da disciplina do pesquisador em um dado período." (GINGRAS, 2016, p. 44). 


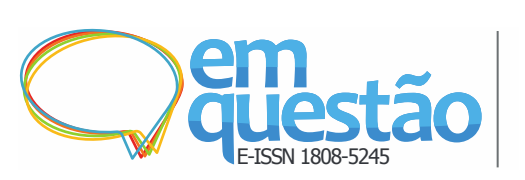

O terceiro capítulo, por sua vez, aborda a avaliação científica, demonstrando a larga trajetória na história da ciência desta atividade e a sua multidimensionalidade, ou seja, os diferentes aspectos que a avaliação pode compreender, como, por exemplo, as publicações, os projetos de investigação, os programas e currículos, os diferentes agrupamentos de pesquisadores (departamentos, centos de pesquisa), bem como, os investigadores individualmente. Neste último caso, Gingras (2016) discute como os indicadores de citação não podem substituir a feitura de julgamentos que levem em conta outras variáveis. O caso de Lysenko (um dos pesquisadores mais citados na década de 1950) é exemplar: antes do total descrédito da proposta de "genética soviética", os trabalhos desse biólogo ucraniano eram, também, citados pelos diversos cientistas que se opunham a ele. Nesse sentido ainda, o autor faz várias críticas ao atualmente popular "índice h" que, segundo Gingras “[...] parece talhado sob medida para satisfazer em primeiro lugar o narcisismo de certos pesquisadores." (GINGRAS, 2016, p. 76).

A questão da especificidade das disciplinas reaparece, nesse terceiro capítulo, na análise dos fatores de impacto das revistas, cujas diferenças, na comparação entre as publicações de ciências sociais e de ciências da natureza, explicam-se pelas características das áreas. Outra discussão relevante é sobre a promoção de práticas desviantes pela adoção de políticas de incentivo com base em indicadores, caso do "cartel de citações" de revistas brasileiras. Os indicadores podem ter efeitos perversos, sobretudo quanto são utilizados não apenas para avaliar, mas também para classificar a pesquisa e os investigadores.

No último capítulo, Gingras (2016) observa que deve haver coerência entre a missão de uma instituição e os indicadores que a avaliem, notando a necessidade de que os indicadores deste tipo apresentem critérios de validade. Assim, volta-se à proposição de alguns critérios desta natureza, como a adequação do indicador ao objeto. Muita válida, também, para o contexto brasileira é a discussão feita pelo autor, ainda neste capítulo, sobre as classificações de universidade em rankings que são construídos a partir de critérios duvidosos e pouco científicos, servindo, principalmente, como instrumento de marketing institucional. 


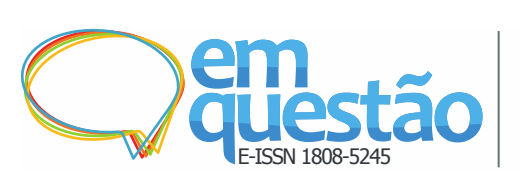

A bibliometria na (e além da) avaliação

Richard Romancini

É possível pensar que algumas discussões poderiam ser aprofundadas, porém, em termos de uma introdução geral à temática, a obra é recomendável, particularmente, aos investigadores que se envolvem em atividades de avaliação científica. A avaliação é uma prática humana feita por seres humanos inseridos em determinado tempo/espaço; daí, a exigência de reflexividade na construção e no uso de indicadores com fins de avaliação em diferentes dimensões. Esta afirmação banal, entretanto, por vezes esquecida, é reforçada pelo livro resenhado. Como nota a breve conclusão da obra, sem um “[...] trabalho prévio de definição da medida, os capitães de navios que se orientam por bússolas ruins [...] se arriscam a soçobrar ao primeiro obstáculo.” (GINGRAS, 2016, p. 124).

Em tempo, a tradução merecia uma revisão por especialista, de modo a corrigir o uso dos termos "diplomas" (p. 41), "agências de meios" (p. 70), "Lyssenko" (p. 73), “indexilidade" (p. 89) e "recaídas" (p. 98), quando, respectivamente, "patentes", "agências de fomento", "Lysenko", "indexicalidade" e "resultados" seriam mais adequados.

\title{
Referências
}

GINGRAS, Y. Os desvios da avaliação da pesquisa: o bom uso da bibliometria. Tradução de Carlos Deanne. Rio de Janeiro: Ed. da UFRJ, 2016.

VAINER, Carlos. Apresentação. In: GINGRAS, Y. Os desvios da avaliação da pesquisa: o bom uso da bibliometria. Tradução de Carlos Deanne. Rio de Janeiro: Ed. da UFRJ, 2016. p. 12-15.

\section{Bibliometrics in (and beyond) research evaluation}

\begin{abstract}
Review of Yves Gingras' book Os desvios da avaliação da pesquisa: o bom uso da bibliometria (The deviations of the research evaluation: good use of bibliometrics). This text highlights the book's character appropriate and concise, which aims to present and discuss the bibliometric methods, particularly in the evaluation of scientific research. The book presents a critical perspective on the subject, without denying the importance of bibliometrics, seeking to discern the appropriate uses of "misuses" due from the use, with low reflexivity, of quantitative bibliometric indicators in the evaluation of science.
\end{abstract}


Keywords: Scientific Evaluation. Bibliometrics. Scientific Research. Scientometrics.

Recebido em: 10/02/2017

Aceito em: 27/04/2017 